\title{
Overseas doctors and the staffing structure of hospitals
}

\author{
DAVID INNES WILLIAMS
}

\begin{abstract}
The introduction of the new immigration rules will considerably reduce the number of overseas doctors available for junior hospital appointments over the next five years. To offset this sponsorship schemes should be offered by universities and colleges comprising training courses, entry to examinations, and hospital appointments, and training programmes should be adapted to make objectives attainable in the four years available to overseas doctors.

Employment of overseas doctors can ease the transition within the staffing structure to fewer juniors and more consultants, but planning is urgently required, and in particular the service and manpower needs of the National Health Service must be considered.
\end{abstract}

\section{Introduction}

The new immigration rules that limit the stay of overseas doctors in the training grades to four years offer them the prospect of a more satisfactory educational programme as it will be possible to reserve good training posts for them without threatening the career progression of doctors who have qualified in Great Britain. The reduction in the number of overseas doctors in the system, however, will expose even more starkly the defects of our present staffing structure, which relies on junior hospital doctors undertaking an excessive proportion of the work. Looking, therefore, to the likely course of events after the introduction of the new rules, these two aspects cannot be considered in isolation, and in adapting hospital staffing the profession will be faced with some harsh decisions. As in all considerations of manpower in relation to training facts are hard to come by and predictions hazardous, but planning for a better structure cannot await statistical precision.

British Postgraduate Medical Federation, London WCIN 3E] SIR DAVID INNES WILLIAMS, MCHIR, FRCS, director

\section{How many overseas doctors will there be?}

Figures derived from registration with the General Medical Council indicate the trends before the introduction of the new rules and assist in estimating the future intake, but the records require careful interpretation. In the 35 years that followed the second world war the number of new registrations of overseas doctors rose steadily, so that by 1976 there were more doctors registered from overseas (3133) than from the United Kingdom (3048). During this period Indian graduates received full registration as of right under reciprocity arrangements and provided a large proportion of the inflow. We have no way of judging how many subsequently left the country, and, although estimates have suggested that about $85 \%$ left, many who came in this period undoubtedly stayed and occupied posts of varying seniority in the hospital service and in general practice. They include major contributors to medical science and practice and some of the most glaring examples of the failure of our postgraduate educational system. The Medical Act of 1978 introduced a new system of recognition for full registration of the degrees of some Commonwealth universities and acceptance for limited registration of a wider group, including doctors from India and the Middle East. The new immigration rules will probably affect the two groups differently.

Table I shows the numbers of those entering under limited registration. The numbers are considerable and have fallen less than might have been expected in view of the difficulty that many have experienced in obtaining appointments of value to them in the hospital service. About $30-40 \%$ of this group have obtained exemption from the Professional and Linguistics Assessments Board examination and have then had their initial job secured.

TABLE I-Numbers of doctors entering under limited registration, 1979-84

\begin{tabular}{|c|c|c|c|c|c|}
\hline \multirow[b]{2}{*}{ Year } & \multirow{2}{*}{$\begin{array}{c}\text { Annual No of } \\
\text { initial } \\
\text { registrations }\end{array}$} & \multicolumn{3}{|c|}{ Annual No of transfers to full registration } & \multirow{2}{*}{$\begin{array}{l}\text { Total on medical } \\
\text { register at } 1 \text { January }\end{array}$} \\
\hline & & Requalified & By experience & Total & \\
\hline $1979^{\star}$ & 1159 & & & & \\
\hline 1980 & 1682 & 83 & 655 & 738 & \\
\hline 1981 & 1671 & 93 & 345 & 438 & 5308 \\
\hline 1982 & 1473 & 78 & 271 & 349 & 5707 \\
\hline 1983 & 1129 & 101 & 360 & 461 & 5928 \\
\hline 1984 & 1123 & 154 & 574 & 728 & 5582 \\
\hline 1979-84 & 8237 & & & $2714(33 \%)$ & \\
\hline
\end{tabular}

^Those registered after 15 February 1979 only. 
The group who have to pass the examination (the pass rate is roughly $30 \%$ ) have more often had to take locum posts, often in a specialty inappropriate to their career intentions. In a survey in 1983 , only $13 \%$ had obtained a substantive post in the specialty of their choice within six months.

Doctors on limited registration can, however, transfer to full registration either by requalifying or by satisfying certain conditions of experience, and in the five years that this scheme has been operating one third have transferred, almost always with the intention of staying in this country (table I). The total number of doctors on limited registration has remained surprisingly constant in the four years that it has been recorded, so presumably two thirds have returned home. Hospital staffing figures for England and Wales (table II), however, show that the number of doctors with limited registration in employment has changed very little, being about 3300 with perhaps 430 in locum posts. It might therefore be reasonable to think in terms of a rate of participation for England and Wales of $68 \%$ of the total number of those on the limited register.

TABLE II-Doctors born overseas on limited registration employed in the National Health Service in England and Wales

\begin{tabular}{lllllll}
\hline Year: & 1979 & 1980 & 1981 & 1982 & 1983 & 1984 \\
No employed: & 3136 & 2976 & 3244 & 3276 & 3360 & 3295 \\
\hline
\end{tabular}

There are, of course, doctors currently in the system, to whom the new rules will not apply, and any new changes will be applied gradually, but it is not unreasonable to suppose that as no overseas doctor can now expect to stay here for a career there will be a 33\% drop in entrants, which is the proportion who have so far transferred to full registration. On this estimate the entry each year would fall from 1100 to 800 , and the outflow would be steady or increase as only four years' training is permitted. Thus the number on the limited register will inevitably fall by the end of five years to perhaps 3200 , and if the rate of participation is unchanged those available for posts in England and Wales will be 2400 instead of 3750 . There is of course a lot of guesswork entailed in this: the fall in numbers could be much greater, and how many come for training alone will depend on the facilities we offer them. For instance, very few currently come to study geriatrics, although many take jobs in this specialty while they are establishing themselves in this country. If, however, this is all we continue to offer trainees who have no more than four years to spend here there will be a rapid fall off, with major consequences for those specialties dependent on doctors on limited registration, of which geriatrics, general surgery, and orthopaedics will be most at risk.

The figures for overseas doctors entitled to full registration by virtue of their primary qualifications in certain Commonwealth countries are less easy to interpret (table III). The totals have not changed appreciably since 1980 . Registration does not, however, imply that these doctors took a post in the United Kingdom or even entered the country. Many transferred immediately or within a few years to the overseas list, whereby they pay no annual retention fee. Table III also shows the numbers from the universities in question on the principal list and on the overseas list at the end of 1984, while table IV gives the numbers of transfers in and out of the overseas list for all registered doctors. There is no way of obtaining the mean duration of stay of doctors in this category from these figures, but clearly most are from Australasia, and it is well known that most stay for less than four years as they are keen to return to their own country to practise. South African graduates form a considerable proportion, and some have remained in Britain for their careers. It will be more difficult for them to do this in the future. The numbers from other universities are small.

The hospital staffing returns issued by the Department of Health and Social Security for England and Wales categorise doctors born overseas

TABLE III-Number of grants of full registration given in 1984, and of overseas graduates entitled to full registration by virtue of primary qualification on the principal list and overseas list at 14 December 1984

\begin{tabular}{lccc}
\hline & & \multicolumn{2}{c}{ No of overseas graduates } \\
\cline { 3 - 4 } Country of origin & No of grants given & Principal list & Overseas list \\
\hline Australia & 428 & 1820 & 6242 \\
Hong Kong & 112 & 378 & 1779 \\
Malaysia & 35 & 161 & 673 \\
New Zealand & 109 & 558 & 1589 \\
Singapore & 21 & 129 & 542 \\
South Africa & 234 & 1614 & 3352 \\
West Indies & 22 & 120 & 176 \\
& & & \\
\hline
\end{tabular}

TABLE IV-Transfers of fully registered doctors (graduates from the United Kingdom and overseas) to and from overseas list

\begin{tabular}{lccc}
\hline Year & Transfers to overseas list & Transfers from overseas list & Net outflow \\
\hline 1970 & 5001 & & \\
1975 & 2713 & 870 & 1843 \\
$1980^{\star}$ & 3013 & 963 & 2188 \\
$1981^{\star}$ & 2980 & 825 & 2155 \\
1982 & 2125 & 812 & 1313 \\
1983 & 1758 & 846 & 912 \\
$1984 \dagger$ & 1533 & 812 & 712 \\
\hline
\end{tabular}

^Figures for 1980 and 1981 were distorted by change of status for Indian graduates. tUp to 14 December 1984.

rather than doctors qualified overseas, and the numbers in the trainee grades who have full registration can be calculated by subtracting those on limited registration. The inflows into this category can be identified but cannot be measured with any accuracy. Table $\mathrm{V}$ shows such figures as are available. Doctors who qualify in Great Britain but were born overseas comprise roughly $11 \%$ of total British medical graduates. A survey carried out by DHSS of doctors registered in 1972, who were followed up eight years later, showed that $76 \%$ of men and $63 \%$ of women who had been born and had qualified in Great Britain were still employed in the National Health Services; among the doctors who had qualified in Great Britain but been born overseas $41 \%$ of men and $54 \%$ of women were still employed in the NHS; while among the doctors who had been born and had qualified overseas $32 \%$ of men and $37 \%$ of women were still employed in the NHS.

TABLE V-Doctors born overseas as trainees. Inflow pattern: new full registrations

\begin{tabular}{lccccc}
\hline & $\begin{array}{c}\text { Graduates from } \\
\text { United Kingdom } \\
\text { born overseas } \\
(11 \% \text { of total })\end{array}$ & $\begin{array}{c}\text { Graduates from } \\
\text { European } \\
\text { Economic } \\
\text { Community }\end{array}$ & $\begin{array}{c}\text { Graduates from } \\
\text { the Common- } \\
\text { wealth }\end{array}$ & $\begin{array}{c}\text { Graduates transferred } \\
\text { from limited } \\
\text { registration }\end{array}$ & Total \\
\hline 1981 & 408 & 187 & 982 & 438 & 2015 \\
1982 & 412 & 265 & 713 & 349 & 1739 \\
1983 & 415 & 317 & 835 & 461 & 2028 \\
1984 & 443 & 316 & 961 & 728 & 2448 \\
\hline
\end{tabular}

The number of doctors coming from the European Economic Community is small but rising (table $\mathrm{V}$ ), and this group is exempt from any immigration controls. With the current oversupply of doctors in several EEC countries this entry could threaten the prospects for British graduates. The numbers of those entitled to full registration by virtue of their primary qualifications are almost certain to fall as a permanent career in this country has become difficult to arrange, and the value of registration without entry to the United Kingdom must be questionable. It might be reasonable to suggest that after five years no more than 600 will be admitted each year, provided that good training programmes can be offered. The numbers transferring from limited to full registration will probably rise in 1985 and perhaps 1986 as those now in the system seek a permanent career, but it must ultimately fall to nearly zero as the four year rule takes effect. The total number of doctors from overseas obtaining full registration in 1984 was surprisingly high, but the falls in the numbers of Commonwealth graduates and those transferring from limited to full registration must certainly outstrip the rise in the graduates from EEC countries by the end of the next five years.

Table VI shows the figures for employment in England and Wales of senior house officers and registrars with full registration who were born overseas. The numbers have been falling steadily, in contrast with the numbers for the same group on limited registration, which have remained steady. The reason for this differential is not apparent, although the take over of posts by doctors born and qualified in the United Kingdom, together with the short duration of stay of the visitors, must be factors.

Taking the predictions for the two categories of registration together, and in spite of major uncertainties, in five years' time there might possibly be

TABLE VI-Senior house officers and registrars born overseas with full registration employed in National Health Service in England and Wales

\begin{tabular}{lllllll}
\hline Year: & 1979 & 1980 & 1981 & 1982 & 1983 & 1984 \\
No employed: & 4805 & 4828 & 4451 & 4141 & 3704 & 3444 \\
\hline
\end{tabular}


2000 fewer overseas doctors employed in the training grades in England and Wales, a reduction of nearly one third, and the fall could be greater unless training opportunities are improved. A number of overseas doctors, of course, are currently in training and will be unable to progress to career posts; their employment must be considered, but it is readily apparent that the shortfall in juniors will be greater than anything that can be made up by graduates from the United Kingdom unless their term of office in the trainee grades is even more prolonged than it is at present. The effects of the new immigration rules will be gradual. As there is at present a cushion of unemployed overseas doctors the first consequence will probably be a reduced availability of locums. The next effect will be on the disciplines that employ many doctors on limited registration but are not their disciplines of first choice. Geriatrics, otolaryngology, ophthalmology, and mental handicap probably fall into this category, but, of the large specialties, general surgery and orthopaedics cannot be immune for long, although sponsorship schemes may help to fill the posts in these fairly popular disciplines.

\section{Training for overseas doctors in Britain}

As immigration to Britain by overseas doctors will now be for only short periods of training better programmes must be offered than at present. Clearly, sponsorship schemes are required to select well qualified applicants and to ensure that they obtain suitable posts. If no national sponsorship scheme is forthcoming then colleges and universities will have to devise arrangements of their own. In the acute specialties, which are those that most overseas doctors wish to study, the schemes could follow the lines proposed by the Council for Postgraduate Medical Education in its submission to the DHSS. A sponsorship organisation inevitably costs money, and the colleges could find the necessary resources only by charging a fee, so that individual doctors would have to see some advantage in sponsorship over operating in the free market. Colleges might well offer package deals, which would include fees for short courses, help in obtaining short term locum appointments, guidance into earmarked posts, and allowances for entry into examinations. Four years is not long for effective training, and in medicine and surgery sponsorship might start with doctors who had already passed the primary FRCS or MRCP part I examination either abroad or in this country on a visitor's permit. Other specialties would need to make other arrangements, but it is important that, for those seeking to obtain junior hospital appointments, there are clearly defined objectives, ending with a diploma that is reasonably attainable in the time available. College diplomas in the specialties, which have in recent years lost some of their credibility, will need to be re-examined.

It should additionally be recognised that some wealthy underdeveloped countries are now willing to pay a sponsorship fee and to support their protégés in a supernumerary capacity. Furthermore, some countries are now sending their postgraduates to Britain for university diplomas or MSc courses lasting up to nine months, even though they have little practical experience. This is more appropriate in the medical than the surgical specialties and at a fairly advanced level, but courses have been successfully organised by several institutes of the British Postgraduate Medical Federation-notably, those of dermatology, neurology, cardiothoracic medicine, dental surgery, and orthopaedics.

The new rules open up the possibility of training overseas doctors in general practice now that the hazard of permanent recruitment into that discipline has been removed, although amending legislation may be required to permit those on limited as opposed to full registration to take trainee posts outside the hospital service. It is doubtful, however, whether the examination for the MRCGP would be an attainable objective.

\section{The staffing structure of hospitals}

A change in the staffing structure of hospitals, aimed principally at increasing the number of fully trained staff in relation to trainees, is already long overdue but is made more urgent by the expected decline in the numbers from overseas and, it is to be hoped, the greater proportion of sponsored doctors. The change is required both to improve the service to patients and to meet the legitimate grievances of British qualified juniors, but strong resistance must be expected, stemming from the likely additional cost to the NHS and the inevitable alteration in the working practice of consultants. Professional and educational bodies therefore, have an important responsibility to facilitate acceptance of the change while at the same time protecting or improving standards of postgraduate education.

Experience in a succession of junior hospital posts remains central to our system of postgraduate training, and as long as this remains the case training needs must interact with the manpower requirements of the NHS. Recent prolonged, inconclusive discussions on "general professional" or "basic specialist" training did not always take this fact into account. Junior hospital doctors are assistants, employed with three main objectives: firstly, to be trained for future career appointments; secondly, to provide first, or later second, on call cover for emergency duties; and, thirdly, to undertake routine medical and basic specialist care in the hospital setting.

All specialties must have a training ladder, and a definition of the numbers for such training is urgently required. But in respect of the two other functions specialties vary greatly. Thus a specialty concerned essentially with consultant reporting, such as histopathology, has only a small emergency or routine element, and the numbers in junior posts can therefore be strictly related to training needs alone. Overseas doctors who are trainees in such specialties should be supernumerary.

The acute specialties-that is, general medicine and general surgery, obstetrics and gynaecology, paediatrics, orthopaedics (with trauma), and anaesthetics (intensive care)-have an inescapable need for juniors to be first on call for emergency duties, and their requirement for young doctors able to perform this function must always outstrip the numbers needed to replace the consultant ranks. Fortunately, experience in the acute specialties is both attractive and valuable to trainees in their early postgraduate years, whatever their ultimate career intentions, so that the service need for young and enthusiastic juniors can usually be met without difficulty; the danger lies in allowing this large number of doctors to see their future within the same acute specialties as, unhappily, is often the case at present. For example, in surgery many excellent training programmes have been devised to attract doctors to the numerous junior posts. As a result 522 new fellowships were granted in 1983 by the royal colleges of surgery to doctors who had qualified in Great Britain, and 422 were granted in 1984 . Yet the number of new consultant appointments available yearly in all surgical specialties, including ophthalmology, is unlikely to exceed 150 . The fellowship examination and appointment as a consultant are of course separated by many years, but such disproportionate numbers bode ill for the career progression of juniors now in post.

Clearly, the number of surgical juniors (excluding preregistration) should be reduced overall with a corresponding increase in the consultant cadre, but there must always be enough juniors to provide a one in three rota for emergency duty, if necessary on a smaller number of sites than at present. Secondly, targeted training appointments in surgery for doctors who qualified in Great Britain, whether senior house officer or registrar, must be more nearly equated to the opportunities for higher training. Thirdly, if additional numbers are required for emergency cover they must be provided either by doctors who qualified in Great Britain and are on multidisciplinary rotations or by overseas doctors in targeted training programmes. Similar considerations would apply to other acute specialties.

The multidisciplinary rotations would be analogous to those now organised for vocational training for general practice, but some would need to include general surgery, obstetrics and gynaecology, orthopaedics, or anaesthetics, which are often excluded from general practice programmes but are nevertheless valuable to all hospital specialists and required for hospital staffing. It is arguable whether all doctors who have qualified in Great Britain should be included in such a multidisciplinary rotation before they embark on a targeted programme. Such a suggestion would be in keeping with the recently advocated period of basic specialist training, although many will consider that a compulsory period of this sort would inevitably add to the already overlong training period and that if a young doctor wishes to embark at an early stage on a particular specialty he should be allowed to do so if he can successfully compete for a place in a specialist rotation. In the major specialties, such as surgery and psychiatry, experience is ordinarily required in a wide variety of subspecialties, which gives contact with a broad range of medical care. By contrast, the sponsored overseas doctors would be coming to this country for specific training and would not be required in the multidisciplinary rotations, which might sometimes make them popular with their consultant chiefs.

Routine medical care and basic specialist treatment in hospitals are provided easily enough where large numbers of juniors are required for emergency cover. Some specialties, however-for instance, longstay geriatrics and mental handicap-have a large element of routine care, but there is no pressing reason why this should be undertaken by trainees. In other specialties, such as otolaryngology, ophthalmology, and some aspects of orthopaedics, and, on the medical side, in diabetic clinics, for instance, a large element of outpatient work and some inpatient care are routine. At present, these are too often left to trainee staff, predominantly those who qualified overseas, many of whom have had long specialist experience but have found no place in higher training programmes. If in the endeavour to correct the ratio of juniors to seniors all this work were to be undertaken by consultants their operative workload or genuinely consultative practice would be so curtailed that there could be serious loss of skill.

In the examples cited above there is a good case for employing a nonconsultant career grade doctor, who would replace a trainee but whose appointment would not jeopardise the expansion of the consultant grade. In the case of long term residential patients receiving medical care a hospital practitioner may be most appropriate, but in the specialties general practitioners will probably not want to participate: the vocational training 
schemes have ensured a wide general experience but usually preclude long periods in a specialty. The associate specialist grade can fulfil this requirement, and opportunities should be available to those unable to get into higher specialist programmes to complete a training with this objective. Alternatively, a grade should be devised, such as the hospital practitioner mark II, that is not so closely linked to consultants on the salary scale but nevertheless gives these doctors an opportunity to provide a most necessary service.

In England and Wales in 1984, there were 1354 senior house officers and 1006 registrars who had been in the grade for four years and over, and these numbers have been rising steadily since 1979 . In orthopaedics, for instance, the number of senior house officers has almost doubled, but at the registrar stage there has been no increase. Many of these are overseas doctors who have had long specialist experience and are capable of giving valuable service but should clearly not be retained in a trainee grade. The opposition to the enlargement of the associate specialist category stems largely from a misapprehension of the role to be adopted: these doctors can replace juniors in their function of providing routine medical care and basic specialist treatment but not in the provision of first on call emergency hospital treatment.

Juniors who have qualified in Great Britain often express fears that the overall reduction in the number of trainees and the reservation of some posts for sponsored overseas doctors will leave many of them unemployed. Certainly, both educational and professional bodies must actively associate themselves with the demand for an expansion of the consultant numbers in the long established specialties as well as in the newer disciplines. It should be pointed out, however, that $46 \%$ of registrars and $38 \%$ of senior house officer in England and Wales are born overseas, that this number will inevitably fall, and that the career prospects of British doctors will be greatly enhanced if they distribute themselves throughout all specialties and all geographical regions of the country. Whether the number of undergraduates in British universities should also be reduced is beyond the scope of this discussion.

\section{Conclusions}

The new immigration rules, together with the established trends, will gradually reduce the number of overseas doctors available for junior hospital appointments. In five years' time there will probably be 2000 fewer overseas doctors, and unless better programmes are offered the fall may be greater and more rapid.

In the absence of a national scheme the royal colleges and universities should offer sponsorship schemes that comprise training courses and entry to examinations as well as help in obtaining hospital appointments.

Training programmes for overseas doctors must be adapted to provide objectives reasonably attainable within four years. Entrants should have had some experience in the specialty of their choice and should have passed the appropriate part 1 examination.

Continuing employment of overseas doctors can ease the transition that is required in the hospital staffing structure to a smaller number of juniors and more consultants, but planning for this transition is urgently needed.

As postgraduate training depends so much on experience in a series of junior hospital posts training programmes must take account of the service and manpower needs of the NHS. The functions required of junior hospital doctors require analysis; some would be performed better by a non-consultant career grade appointment.

I am indebted to the registrar and staff of the General Medical Council for the figures on registration. The figures on staffing in England and Wales are derived from the annual hospital staffing reports issued by the Department of Health and Social Security.

\section{Medicolegal}

\section{Pertussis claim dismissed}

\section{BY OUR LEGAL CORRESPONDENT}

A claim for damages brought on behalf of a severely brain damaged boy has been dismissed in the Edinburgh Court of Session on the ground that the plaintiffs failed on the balance of probabilities to prove that the injury was caused by pertussis vaccine. ${ }^{1}$

The action was brought on behalf of Richard Bonthrone, now aged 9. At the age of 4 months he had been vaccinated against whooping cough, diphtheria, and tetanus. Three months later he was given a booster. Nine days after the second vaccination he began to have convulsions. Formerly alert and playful, he is now profoundly mentally handicapped; he has a mental age of 6 months, no useful vision, no intellectual capacity, and is prone to convulsions. All his food has to be liquidised. His only enjoyment in life is said to be in recognising his mother's voice and going for car rides.

Damages had been provisionally agreed between the parties subject to liability at $£ 145000$. As a result of the court's decision no damages were awarded.

Dr John Stephenson of the Royal Hospital for Sick Children in Glasgow, giving evidence, said that it was a fallacy to attribute the cause of encephalopathy to a vaccine merely because of a time association. He said that the more he had studied the problem the more the idea of a link between the triple whooping cough vaccine and brain disorders had seemed "to approach vanishing point". $\mathrm{He}$ accepted that the triple vaccine probably could cause acute neurological reactions but, contrary to his previous view, he was unconvinced that permanent damage resulted.

Professor David Miller of St Mary's Hospital, London, said that the risk of a child developing encephalopathy nine days after being vaccinated was so small as to be incapable of statistical measurement.

An appeal is expected.

Ten thousand pounds has already been paid out for the benefit of Richard Bonthrone under the Vaccine Damage Payments Act, 1979. That Act was passed in response to public alarm at a number of reported cases of brain damaged children in the 1970s. It provides for a payment of $£ 10000$ out of money provided by parliament if the Secretary of State is satisfied "that a person is, or was immediately before his death, severely disabled as a result of vaccination against any of the diseases to which this act applies." Any dispute as to entitlement is to be settled outside the courts by a medical tribunal. The $£ 10000$ payment provided is not described as compensation, and it is not related to the damage suffered or to the needs of the complainant. Inflation has substantially eroded the value of the payment since 1979.

The Act clearly states that the payment is to be made only if the Secretary of State is satisfied that the claimant was disabled "as a result of vaccination." If the Secretary of State pays regard to the evidence given in the court of session the statutory payments may be more difficult to obtan in future.

\section{Reference}

1 Anonymous. Parents fail in whooping cough vaccination test case. The Times 1985 Aug 31:3 (cols 1-2). 